\title{
Residential Lighting Performance Indicators
}

\author{
Júlia Silva de Moraes ${ }^{1}$ | Adrián Muros Alcojor ${ }^{2}$ | Leonardo Salazar Bittencourt ${ }^{3}$ \\ Recibido: 17-07-2020 | en su versión final: 09-11-2020
}

\begin{abstract}
One way to evaluate lighting efficiency considers the use of lighting indicators, to guide design decisions. Nevertheless, there are not many tools allowing for an integration of quantitative and qualitative aspects of artificial lighting, mainly for the residential use, that has a deficient approach, falling short of the other architectural uses in the standards of artificial lighting. The aim of this paper is presents a new proposal to evaluate artificial lighting performance that meets the demands of visual comfort, health, and assures an adequate energy performance. In an integrated manner, it has been joined three aspects involved in the quality of a lighting design. The methodology adopted is based in a parametric analysis of the performance consider different artificial lighting systems in a typical living/dining room. It is supported by computer simulations, aiming to investigate the influence of lighting design variables on energy performance, visual comfort and health in these rooms. The results reveal a set of intrinsically related indicators. The band with the best results was obtained with a Lighting Power Density indicator (LPD) of between 3.5 and $10 \mathrm{~W} / \mathrm{m}^{2}$, includes a set of technical requirements that present high efficiency levels of the light, the colour reproduction (CRI) a warm colour temperature. The residential lighting performance indicators may contribute to the improvement of the standards with reflexes on the professional activities of lighting designers.
\end{abstract}

Keywords: lighting indicators; energy performance; visual comfort; health

Citation

\section{Indicadores de rendimiento de iluminación residencial}

Resumen

\begin{abstract}
Una forma de evaluar la eficiencia de la iluminación, considera el uso de indicadores de iluminación para guiar las decisiones de diseño. Sin embargo, no existen muchas herramientas que permitan una integración de aspectos cuantitativos y cualitativos de la iluminación artificial, principalmente para el uso residencial, que tengan un enfoque deficiente, quedando a la altura de los otros usos arquitectónicos en los estándares de iluminación artificial. El objetivo de este trabajo es presentar una nueva propuesta para evaluar el rendimiento de la iluminación artificial que satisfaga las demandas de confort visual, salud y asegure un adecuado rendimiento energético. De manera integrada, se han unido tres aspectos involucrados en la calidad de un diseño de iluminación. La metodología adoptada se basa en un análisis paramétrico de la actuación, considerando diferentes sistemas de iluminación artificial en un salón-comedor típico. Está respaldada por simulaciones por ordenador, con el objetivo de investigar la influencia de las variables de diseño de la iluminación en el rendimiento energético, el confort visual y la salud en estas habitaciones. Los resultados revelan un conjunto de indicadores intrínsecamente relacionados. La banda con mejores resultados se obtuvo con un indicador de densidad de potencia lumínica (LPD) de entre 3,5 y $10 \mathrm{~W} / \mathrm{m}^{2}$, que incluye un conjunto de requisitos técnicos que presentan altos niveles de eficiencia de la luz, la reproducción del color (CRI), un color cálido la temperatura. Los indicadores de rendimiento de iluminación residencial pueden contribuir a la mejora de los estándares con reflejos sobre las actividades profesionales de los diseñadores de iluminación.
\end{abstract}

Palabras clave: indicadores de iluminación; desempeño energético; comodidad visual; salud

1 Architect, Doctor, Instituto Federal da Bahia, IFBA (ORCID: 0000-0002-6002-5934, WoS ResearcherID: AAG-1430-2021), ${ }^{2}$ Architect, Doctor, Universitat Politècnica de Catalunya, UPC (ORCID: 0000-0002-0167-2904), ${ }^{3}$ Architect, Ph.D., Universidade Federal de Alagoas, UFAL (ORCID: 0000-00022294-6580, WoS ResearcherID: N-2961-2014). Contact e-mail: julia@ifba.edu.br 


\section{Introduction}

The efficiency of artificial lighting systems can be evaluated through the use of performance indicators. These indicators are taken as benchmarks that assist designers with the lighting performance they wish to achieve.

Visual comfort indicators express favourable conditions to the development of residential activities. Energy efficiency is the result of two complementary aspects. The first is related to the performance of lighting equipment (light bulbs, luminaires and accessories). The second depend on the characteristics of the built environment (shape, dimensions, internal surface finish and window typology) as well as the behavioural aspects of users.

Moraes, Muros Alcojor and Bittencourt (2018; 2020) investigated the main Residential Artificial Lighting (RAL) indicators. Residential environments demand indicators of health and visual comfort predominantly described in IES (2013) and SSL (2009; 2013) lighting manuals, since specific regulations for residential buildings (CEN, 2011; ISO, 2002) were not found in the literature.

Energy efficiency indicators are primarily present in standards and codes. Among the indicators analysed, the Lighting Power Density indicator (LPD) is the most common parameter for the nonresidential buildings (ASHRAE, 2019) while luminous efficacy is the indicator most applied to residential buildings (CEC, 2019).

Among the energy efficiency indicators, for residential environments, the California Code (CEC, 2019) stands out from other publications, since it establishes a set of indicators that associate visual comfort criteria, health and lighting system efficiency in an integrated way. These parameters (CEC, 2019; CLTC, 2016) can be observed by establishing luminous efficacy, the Colour Rendering Index (CRI) and Colour Temperature, as the main criteria to define high efficiency lighting (Moraes, Muros Alcojor and Bittencourt, 2018). The code (CEC, 2019) only presents criteria related to the light source and goal to the maintenance of light's effect on the human circadian system in homes (Rea et al., 2010; SSLerate, 2016).

The same authors (Moraes, Muros Alcojor and Bittencourt, 2018; 2020) report the absence of a set of residential indicators that associate visual comfort and energy efficiency. This would lead designers to consult parameters of international standards (ASHRAE, 2019; CEN, 2011; ISO, 2002) set for other architectural uses, such as commercial, service and public, often with performance criteria different to that considered for homes. The analysis identified that this gap is present worldwide. The commercial and service types present indicators widely described in the literature (ASHRAE, 2019; CEN, 2011; ISO, 2002). However, the residential use has a deficient approach, falling short of the other architectural uses.

Aiming to contribute fulfil the gap identified in lighting standards, and other aspects related to the use of these benchmarks in residential environment simulations, this study widens the investigation on normative benchmarks for residential artificial lighting design (Moraes, 2018; Moraes, Muros Alcojor and Bittencourt, 2018; 2020), from an analysis of the artificial lighting indicators obtained through computer models and aspects related to the use of these normative benchmarks. The discussions presented here are taken from an academic work (Moraes, 2018).

This paper presents a new proposal in which the artificial lighting indicators express the integrated performance of visual confort, health and efficiency on Residential Artificial Lighting (RAL). The development of RAL indicators offers an important tool for architectural design, post-occupation assessment, energy and urban planning, as it allows guiding decisions from the point of view of the energy efficiency of lighting systems, health and user comfort. Such solutions contribute to meeting the future demand for electricity and the well-being of society, considering the best use of this resource in residential environments.

ACE, 15 (4.5) CC BY-ND 3.0 ES | UPC Barcelona, España | Residential Lighting Performance Indicators. DOI 2 http://dx.doi.org/10.5821/ace.15.45.9536 


\section{Methodology}

The methodology adopted to achieve the objective of developing a set of procedures to evaluate the performance of artificial lighting that might expresses the integrated performance of visual comfort, health and efficiency on Residential Artificial Lighting (RAL) systems, consists of a comparative analysis of its performance (Moraes, 2018).

The methodological procedures to formulate these indicators are based on parametric analyses of the impact produced by the different configurations of the form, layout, organization and localization of the lighting system installation in the environment. A set of computer simulations was performed considering various living/dining room spatial configurations in residential buildings.

The parameters used in the simulations were considers three items, namely: I) residential environment; II) human factors related to health and visual comfort; III) lighting systems, types and spatial arrangements of the luminaires. By gathering this information, a parametric analysis was made possible, incorporating the influence exerted by each of these variables on lighting performance.

\subsection{Residential environment}

This study considers the living/dining room, representing common solution in residential spaces. Multiple activities exerted in the same environment were considered. For the reasons presented, the living/dining room was selected as the environment where computer simulations of the integrated performance of visual comfort, health and energy efficiency were carried out (Figure 1).

Typical reflectance values of surfaces used in Brazilian homes is 80/80/40 in relation for the ceiling, wall and floor, respectively. This reflectance values (80) are also applied to the furniture - tables, sofas, rugs, textiles etc. The natural lighting is omitted in the entire simulation process.

Figure 1. Living/dining room

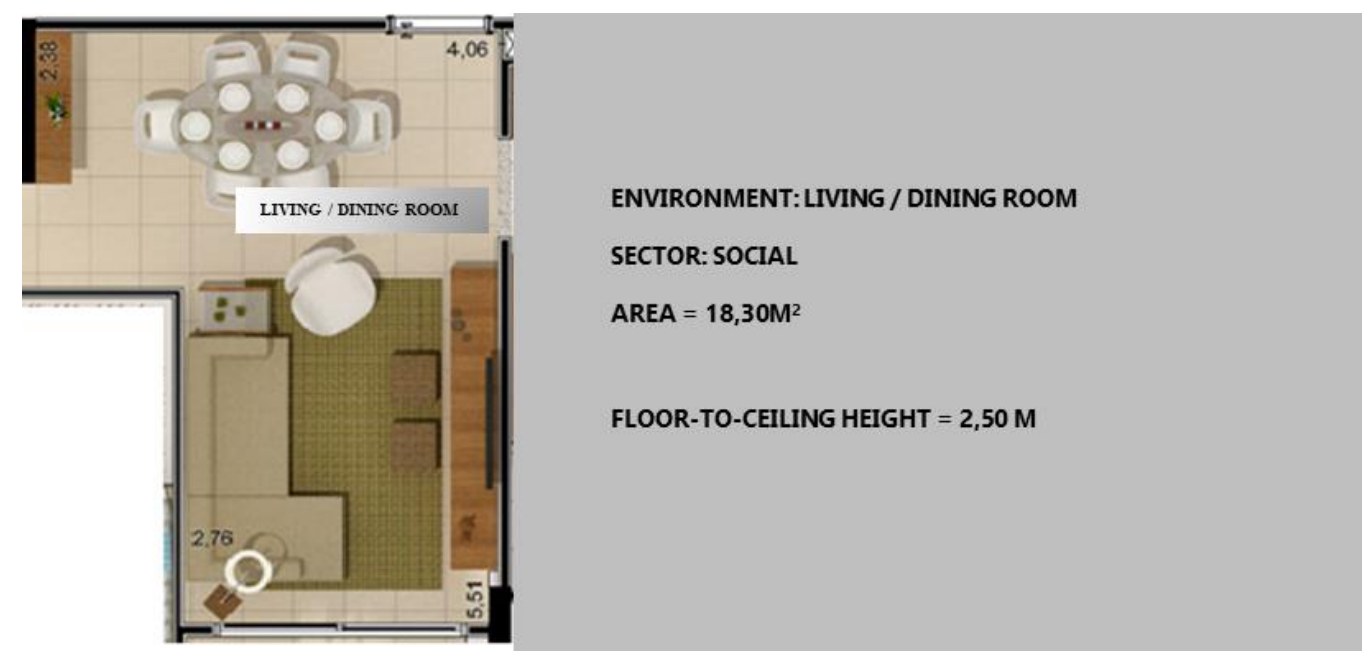

Source: Prepared by the authors. Adapted from Moraes (2018).

\subsection{Human factors}

This study intends to identify best solutions for residential environments, correlating human factors and establishing metrics to be followed that could contribute towards visual comfort and health in environments and the efficiency of lighting systems. Among the parameters to be established, the characteristics related to light and visual comfort and health criteria will be described. 
LED use was considered in this research, particularly "high efficiency" solutions. The requirements most applicable to this research are described by the CLTC (2016), since these have already been validated for homes in California - USA (CEC, 2019) in order to assist the visual condition of the observer in terms of health and Circadian light (Rea et al., 2010).

The concept of "high efficiency" (CEC,2019; CLTC, 2016) for homes includes a set of technical requirements that present high efficiency levels of the source, the CRI and warm colour temperature. Bringing these requirements together is considered pioneering in establishing efficiency, heath and visual comfort metrics in homes, and including research on the effects of light on the human biological clock.

The literature consulted demonstrates that adequate specification of the colour temperature of light sources contributes towards maintaining the activity/rest cycle in residential environments (Rea et al., 2010; Figueiro, Nagare and Price, 2018; Nagare, Plitnick and Figueiro, 2019). The high CRI seeks to respond to colour visualization, which is fundamental for the wide range of residential activities, users' preferences and ages.

Lighting manuals (IES, 2013; SSL, 2009; SSL, 2013) comprehensively present in residential activities. The illuminances required depend on the activity carried out, the user's age, subjective preferences and other factors related to visual comfort and health. Since residential environments are intended for multiple activities and are subject to individual preferences and ages, it was decided to establish the concept of an initial average illuminance higher than 100 lux, which may reach other intermediary or higher levels during the formation of the light scenarios examined.

\subsection{Lighting systems}

Residential Artificial Lighting (RAL) requirements were determined, considering light sources, the lighting systems that form them and their layout in the environment. In the search for more appropriate residential lighting systems, the principle of the best technology available was selected, in order to reconcile best practices for energy and the visual performance of lighting in residential environments. Observing these assumptions, LED technology was selected, since it presents characteristics such as high performance, is widely studied (IES, 2013; SSL, 2009) and has a wide range of applications in homes.

In a search to adjust "high efficiency LED" to the reality of the Brazilian lighting market, the criteria established by the CLTC (2016) for the residential sector were described with CRI adaptation, adjusted to higher than or equal to $80 \%$. The LED source requirements - such as temperature and colour reproduction, among others included in energy performance - are related to human factors, since the definition of the source characteristics unites the desired visual performance conditions. The main requirements are presented in Table 1.

When relating the luminous efficacy indicator $(\eta)$ to visual comfort parameters, the California code (CEC, 2019; CLTC,2016) contributes towards the concept defended in this study: the artificial lighting of residential environments requires integrated indicators that guarantee health, visual comfort and energy performance.

Table 1. Main LED source requirements

\begin{tabular}{|c|c|c|}
\hline Parameters & Limits & Lighting Performance \\
\hline \hline Light sources: & LED & - \\
\hline Luminous efficacy $(\eta):$ & $\geq 45$ lumens $/ \mathrm{W}$ & Energy performance \\
\hline Colour temperature $(\mathrm{Tc}):$ & $\leq 4.000 \mathrm{~K}$ (preference for $3.000 \mathrm{~K})$ & Visual confort and health \\
\hline CRI: & $\geq 80 \%$ (preference for $\geq 85 \%)$ & Visual confort and health \\
\hline
\end{tabular}

Source: Prepared by the Authors. Adapted from CLTC (2016).

ACE, 15 (4.5) CC BY-ND 3.0 ES | UPC Barcelona, España | Residential Lighting Performance Indicators. DOI: 
The effect produced by different systems depends on the lighting design. With the aim of making these choices less subjective, and seeking to systematize and unify these ways of specializing artificial light is fundamental, in order to define a logic within this repertoire that is associated to artificial light and architecture.

Complementary to the manuals (IES, 2013; SSL, 2009), with an emphasis on the lighting effect produced in the space (Muros Alcojor, 2012). These are considered more comprehensive, if compared to classifications based on the object (the luminaire), since they consider the space/effect relation of the lighting produced in the inhabited environment. This systematization was considered the most appropriate for this study, since it allows the practical application of many lighting effect possibilities - variations that express many preferences and needs of the residential universe (Figure 2).

It was opted for a classification with emphasis on the lighting effect produced in the space, which consists of the FORM, LAYOUT and ORGANIZATION aspects (Muros Alcojor, 2012) of lighting systems in the environment. In this paper, it was expanded, so that it was applicable to lighting in residential environments, including the specification of the assembly LOCATIONS of the systems contained in the environment: (I) horizontal planes, the ceiling and floor; (II) vertical planes: walls and (III) other arrangements in the space, with the potential to organize the lighting systems in the environment (Figure 2).

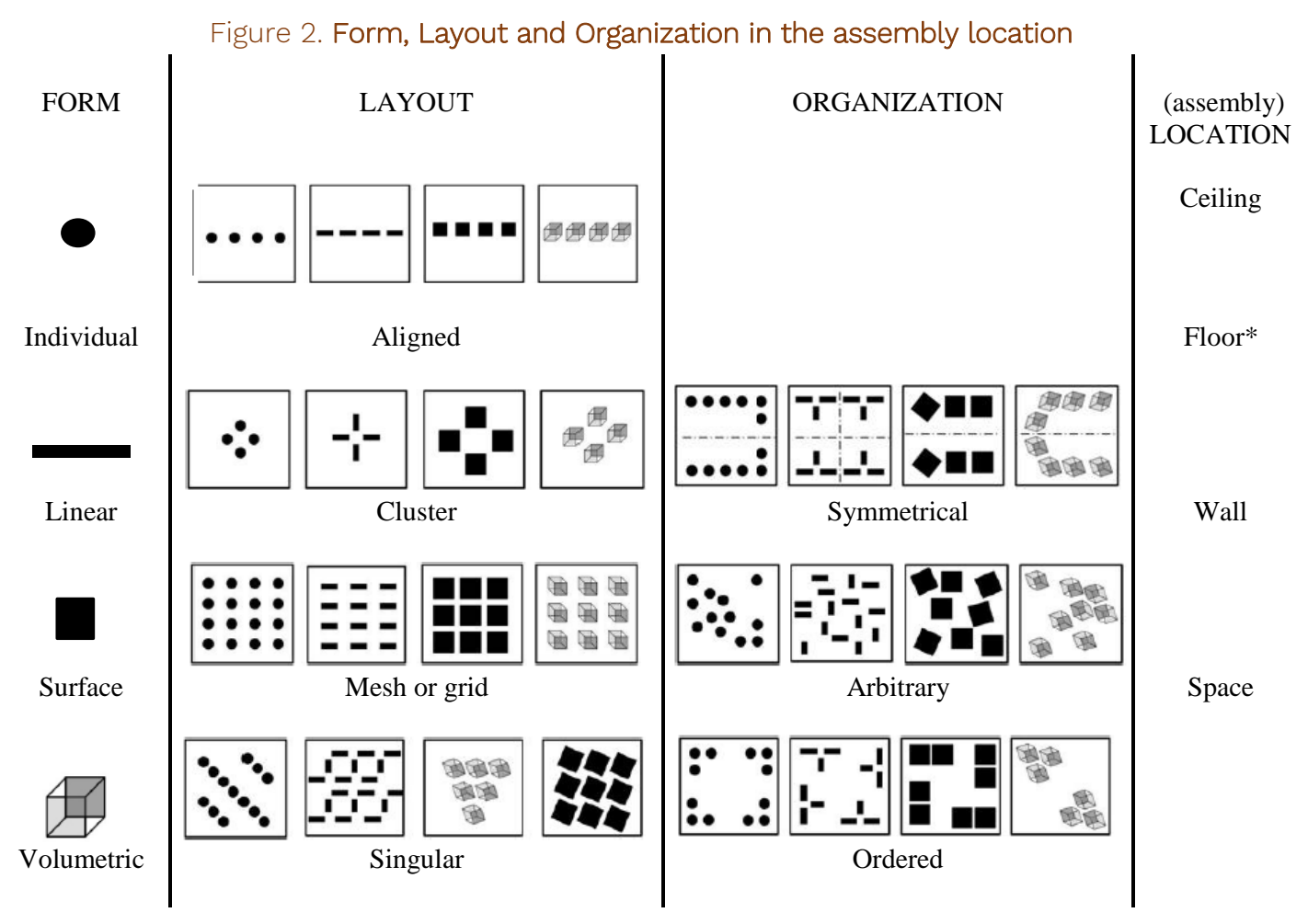

Note: * The assembly LOCATION formed by the floor was not included in the study. Source: Prepared by the Authors. Adapted from Muros Alcojor (2012).

The forms presented are used for spatial organization in the architecture, enabling some compositional criteria between the system form and inhabited environments to be recognized in this classification. Figure 3 demonstrates the application of the FORM, LAYOUT and ORGANIZATION (MurOs Alcojor, 2012) classification in residential environments.

Figure 3. Application of the Form, Layout and Organization classification in residential environments

ACE, 15 (4.5) CC BY-ND 3.0 ES | UPC Barcelona, España | Residential Lighting Performance Indicators. DOI: 5 http://dx.doi.org/10.5821/ace.15.45.9536 


\section{ACE Architecture, City and Environment}

E-ISSN 1886-4805

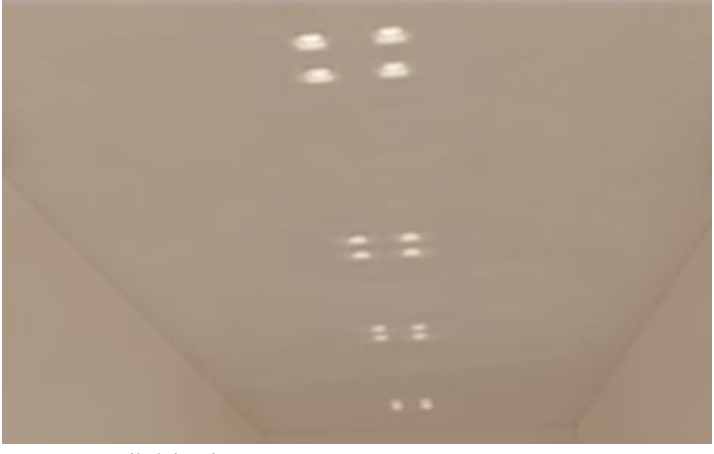

FORM: Individual

LAYOUT: Cluster

ORGANIZATION: Ordered

Source: Prepared by the authors.

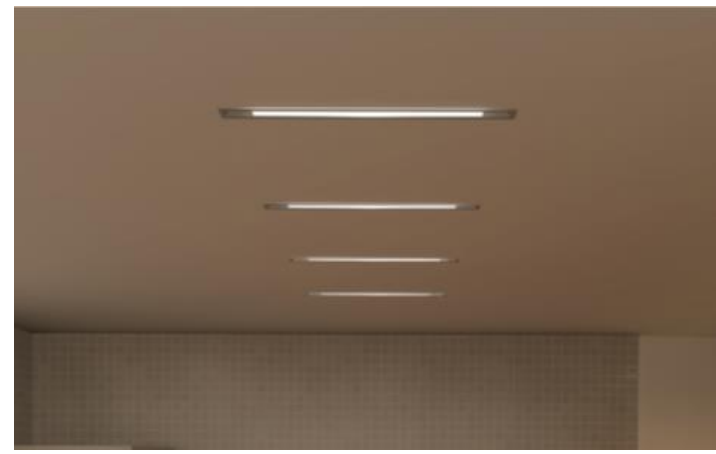

FORM: Linear

LAYOUT: Aligned

ORGANIZATION: Ordered

Figure 4 presents an example of a residential environment where the lighting systems are installed in three assembly LOCATIONS. It is highlighted that the floor was not included, since it was considered minimally recurrent in the residential typology proposed in this study (Moraes, 2018).

Figure 4. Assembly locations of the luminaires in the ceiling, on the wall and in the space

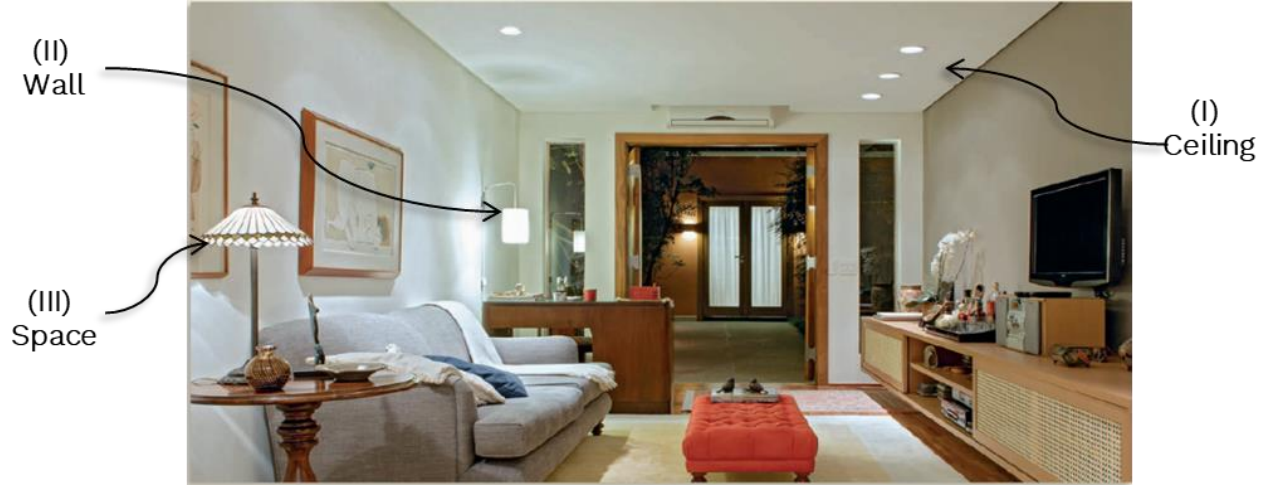

Source: Prepared by the authors. Adapted from Marcelo Kahn (Degra, 2014) and Moraes (2018).

The choice of lighting systems used the luminaire catalogue available on DIALux evo 8.0 (DIAL GmbH, 2018) with assistance from the LUMsearch DIAL tool (DIAL GmbH, 2019). Companies with open data and standardized by IES (2013) can be found on the LUMsearch DIAL database. The luminaires and photometric characteristics were organized by the basic FORM and scenario in which they are inserted, and this aspect is addressed below, through the composition of residential light scenarios. In order to achieve the objectives of this study, a light scenario proposal was developed that grouped the lighting systems together according to the function they exercise in the environments. These scenarios were divided into three interrelated groups: Light 1 - LEADING; Light 2 - COMPLEMENTARY to the leading light; and Light 3 - SUPPLEMENTARY. The characteristics of each group are described in Table 2.

Table 2. Lighting Function

\begin{tabular}{|l|l|}
\hline Parameters & \multicolumn{1}{c|}{ Lighting Function } \\
\hline \hline Light 1 (L1): LEADING & Aims to meet the visual and functional needs performed in the environment. \\
\hline Light 2 (L2): COMPLEMENTARY & $\begin{array}{l}\text { Complements the leading light for other visual activities that require greater } \\
\text { luminosity, to highlight objects and other aspects related to the lighting highlight. }\end{array}$ \\
\hline Light 3 (L3): SUPPLEMENTARY & Includes the lighting produced for aesthetic and occasional effects. \\
\hline
\end{tabular}

Source: Prepared by the Authors. Adapted from Moraes (2018).

ACE, 15 (4.5) CC BY-ND 3.0 ES | UPC Barcelona, España | Residential Lighting Performance Indicators. DOI 


\subsection{Matrix formed}

Different arrangements were proposed in the living/dining room environment, with the LEADING LIGHT lighting system, layouts and organizations were then applied for the various locations: the ceiling, the wall and in the space. The same criteria were used for the grouped systems, as COMPLEMENTARY to the leading light, implementing the FORM, LAYOUT and ORGANIZATION classification in the ceiling, on the wall and in the space, with five examples of LOCATIONS of use. This was also implemented with the SUPPLEMENTARY lighting. Therefore, the lighting system combinations allowed the creation of nearly one thousand light scenarios for the living/dining room. Figures 5 and 6 summarizes the composition of the scenarios formed for the living/dining room.

Figure 5. Light scenario composition in the living/dining room

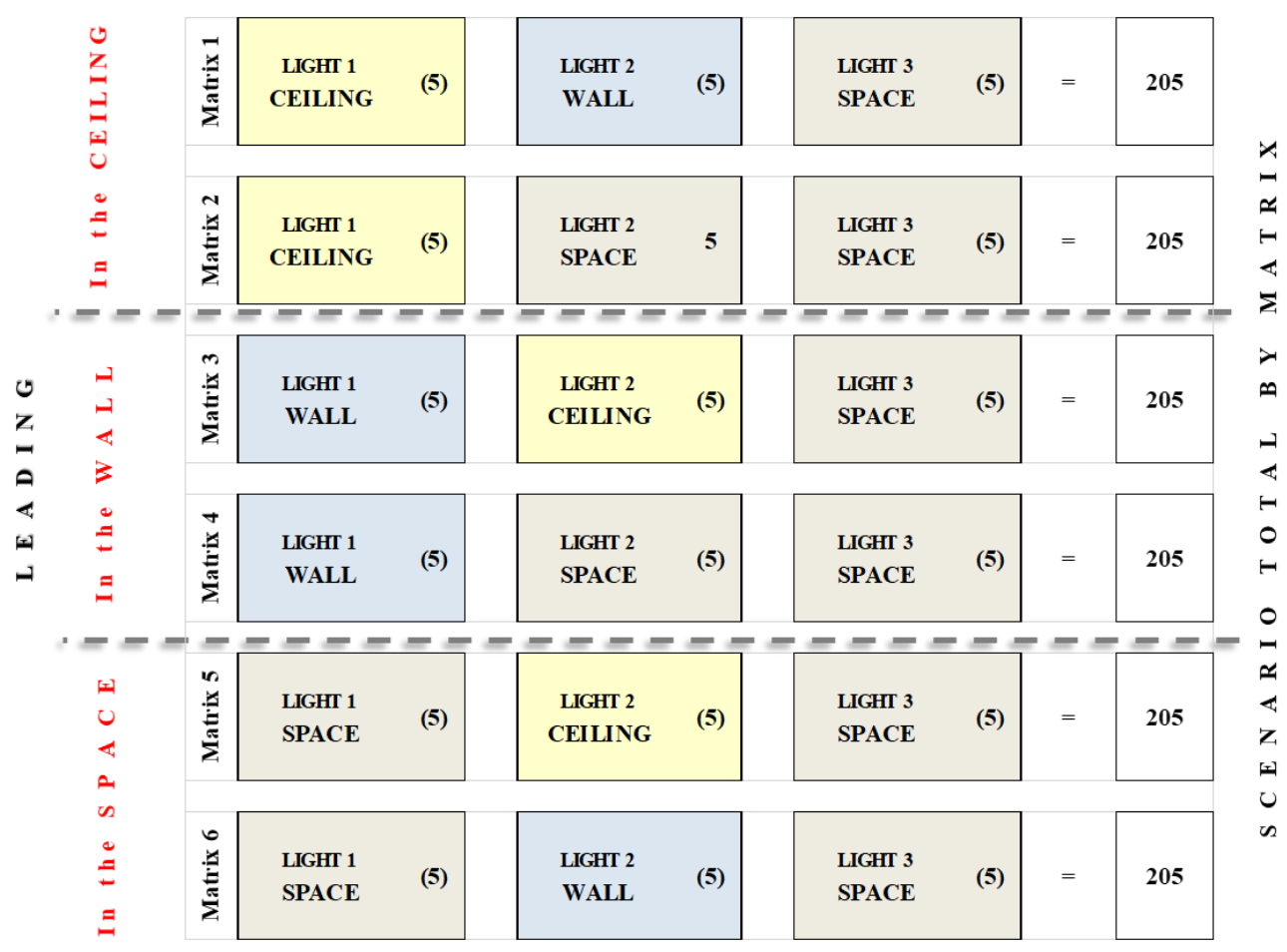

Source: Prepared by the Authors. Adapted from Moraes (2018).

Figure 6. Matrix formed by the scenarios with the function of Complementary lighting, using distinct assembly Locations

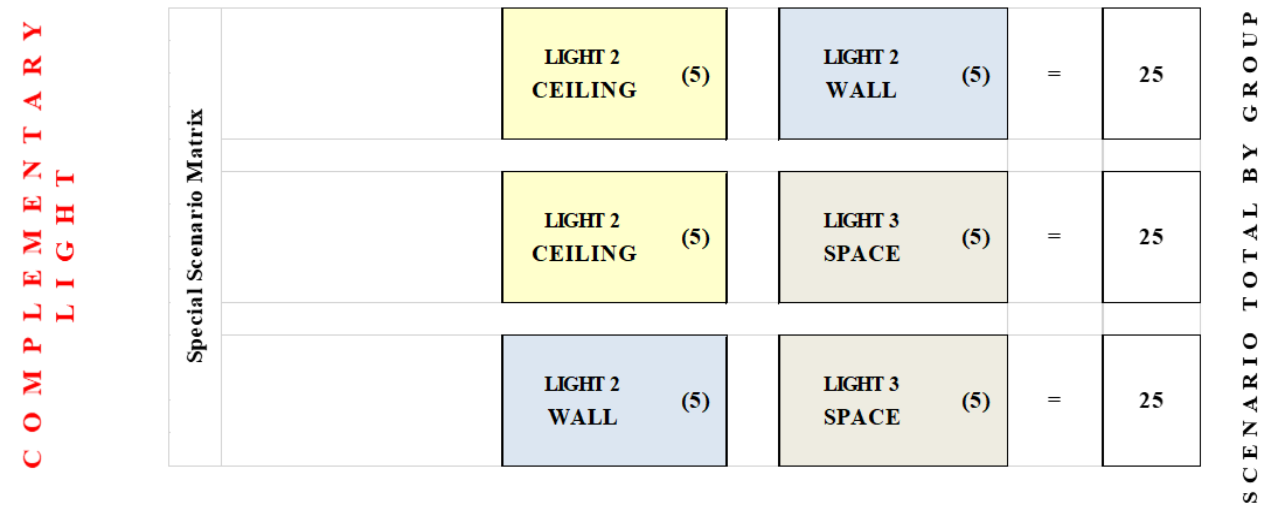

Source: Prepared by the Authors. Adapted from Moraes (2018).

ACE, 15 (4.5) CC BY-ND 3.0 ES | UPC Barcelona, España | Residential Lighting Performance Indicators. DOI: 7 http://dx.doi.org/10.5821/ace.15.45.9536 
Matrix 1 and 2 have the PROTAGONIST LIGHT installed on the ceiling, varying the installation location of the COMPLEMENTARY AND SUPPLEMENTARY LIGHT. The same occurs in matrices 3 and 4, which have the PROTAGONIST LIGHT installed on the wall and in matrix 5 and 6, installed in the space (Figure 5). Other interaction possibilities were also investigated, such as the relation with the COMPLEMENTARY LIGHT, installed in different assembly locations - as demonstrated in Figure 6. In the absence of a LEADING LIGHT, these systems may meet the needs of lighting levels allocated for the activities exercised. Examples of the scenarios formed by this principle will be presented in item 3.2 Scenario comparison.

\subsection{Performance analyses integrating the simulations}

The visual and energy performance analyses of the scenarios considered were undertaken in two ways. The first are environmental illuminance analyses. The second is the energy efficiency of the varying scenarios examined. Initially, meeting the visual comfort and health metrics described in the human factors item was established as the criterion for the models. Thus, all of the simulated models were based on meeting these metrics, ensuring that the illuminances, colour temperature and CRI recommended by the literature consulted were achieved.

These models were then simulated on DIALux evo 8 lighting design software (DIAL GmbH, 2018), in order to evaluate their energy performance, in accordance with the LPD obtained in the simulation. The result for each model can have its performance in relation to energy efficiency compared with the other models, since they all meet the health and visual comfort criterion.

LPD values are processed automatically by the software during the simulation. The results are provided in the technical reports issued by the program. In order to obtain the more than one thousand arrangements created, we opted for procedures that were divided into four stages, namely: (I) Simulation of the scenarios obtained by the environment lighting function (LEADING, COMPLEMENTARY and SUPPLEMENTARY), corresponding to the models presented above (Figure 5); (II) Formation of a digital database, grouping together the results of the energy performance of the scenarios mentioned in the previous item, in LPD; (III) A simple combination of the energy performance of the different scenarios cited, using electronic spreadsheets for this purpose.

Four parameters that influence the RAL were elected for this study, which are used in the configuration of the simulation model. The matrix is centred on the variability of the energy performance, provided by different lighting systems, with emphasis on the three light scenarios (LEADING, COMPLEMENTARY and SUPPLEMENTARY LIGHT) and their possible variations (Figure 7).

Figure 7. Summary of the base model parameters

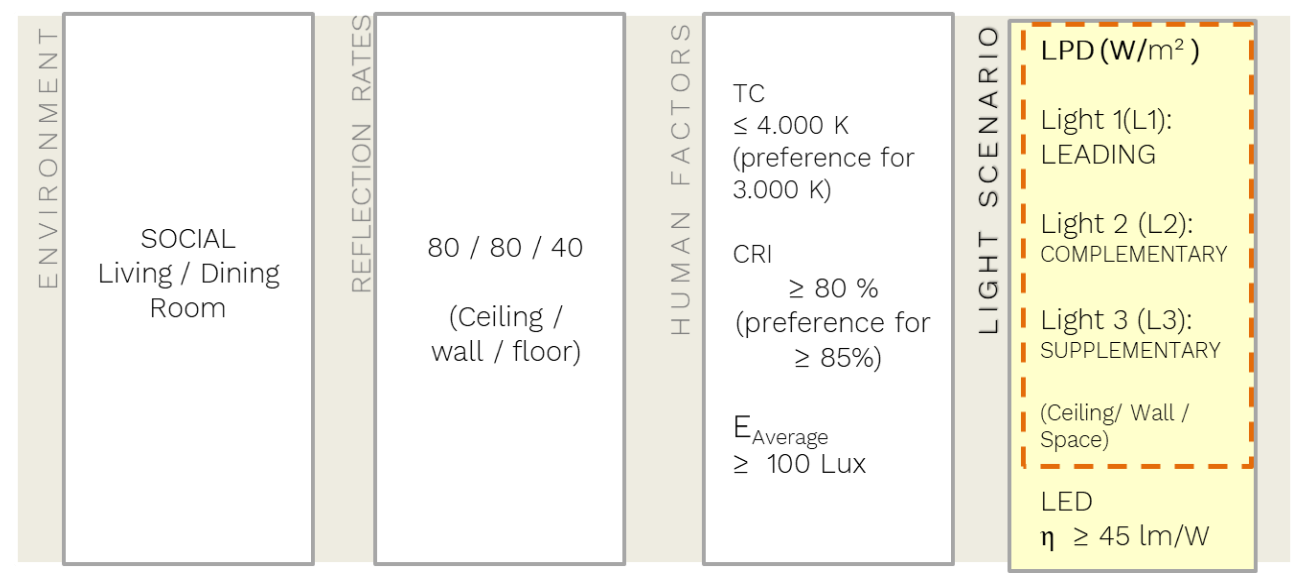

Definition: $E_{m}=$ illuminance avarege (lux). Source: Prepared by the Authors. Adapted from Moraes (2018).

ACE, 15 (4.5) CC BY-ND 3.0 ES | UPC Barcelona, España | Residential Lighting Performance Indicators. DOI: 


\section{Results and discussion}

The living/dining room may be considered the environment in which lighting is most subject to individual preferences. Since the living/dining room is a multiple use space, the construction of light scenarios that provide a wide range of possibilities is important.

\subsection{Energy performance of the group of scenarios formed}

In the case of the living/dining room, interaction between the lighting systems presented is approached, using the LEADING, COMPLEMENTARY and SUPPLEMENTARY light combination. The results of the groups formed by simulation matrixes 1 to 6 (Figure 6) were grouped together in three LPD performance bands ( 0 to 5,5 to 10 and 10 to $15 \mathrm{~W} / \mathrm{m}^{2}$ ), as demonstrated in Figure 8.

The LPD percentages obtained by the light scenarios indicate a value of between 5 and $10 \mathrm{~W} / \mathrm{m}^{2}$ as the band that brings together the majority of the light arrangements formed. The 10 to $15 \mathrm{~W} / \mathrm{m}^{2}$ band represents the lowest percentage of scenarios, in relation to the other bands.

It would be reasonable to suggest a LPD benchmark of approximately $10 \mathrm{~W} / \mathrm{m}^{2}$, as the most predominant of the light scenarios conducted in this paper. A LPD of up to $8 \mathrm{~W} / \mathrm{m}^{2}$ may be attributed as corresponding to the energy performance of the group of scenarios formed by the four visible geometric forms developed in this work (Moraes, 2018).

Figure 8. Light scenarios in percentages per segment

$\begin{array}{ccccccc}\mathbf{L P D}\left(\mathbf{W} / \mathbf{m}^{2}\right) & \mathbf{M 1} & \mathbf{M 2} & \mathbf{M 3} & \mathbf{M 4} & \mathbf{M 5} & \text { M6 } \\ 0-5 & 22 \% & 24 \% & 14 \% & 15 \% & 29 \% & 29 \% \\ \mathbf{5}-\mathbf{1 0} & \mathbf{6 1 \%} & \mathbf{6 0 \%} & \mathbf{6 7 \%} & \mathbf{6 8 \%} & \mathbf{7 1 \%} & \mathbf{7 1 \%} \\ 10-15 & 16 \% & 16 \% & 19 \% & 17 \% & 0 \% & 0 \%\end{array}$

LPD - light scenarios

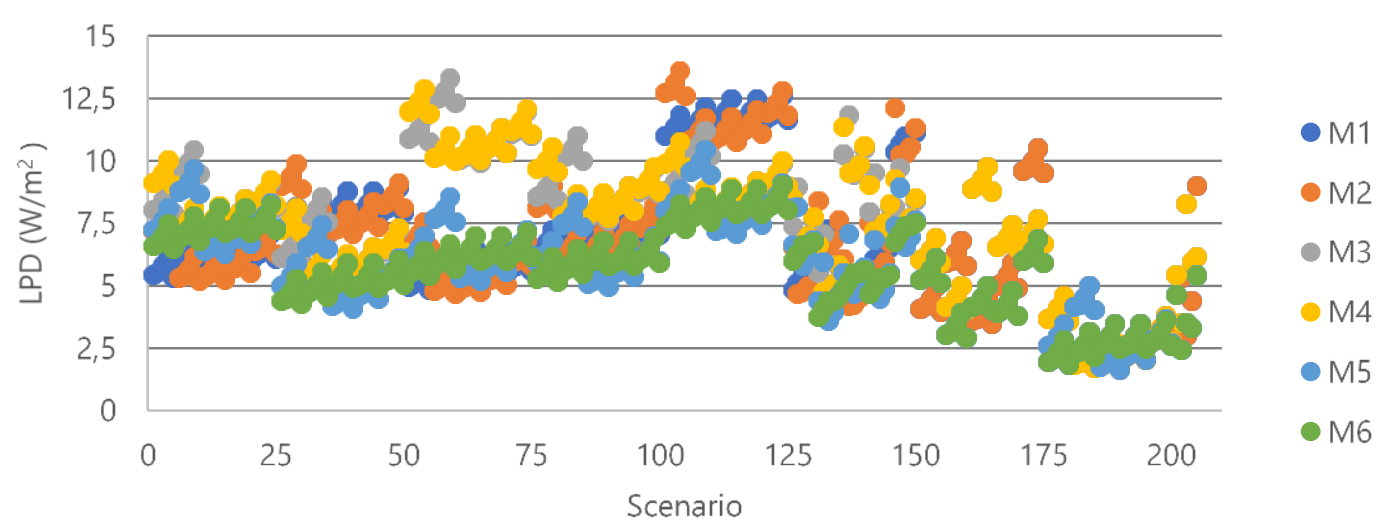

Definition: Matrix 1 (M1); Matrix 2 (M2); Matrix 3 (M3); Matrix 4 (M4); Matrix 5 (M5); Matrix 6 (M6). Source: Prepared by the Authors. Adapted from Moraes (2018).

\subsection{Scenario comparison}

The fundamental aspect defended in this research is the comparison of the energy performance of the various living/dining room scenarios examined in RAL. The selection of parameters presented above is proposed for this purpose, which may assist in a comparison of the visual comfort performance and lighting efficiency. 
The energy performance obtained in the environment in LPD, the performance bands, the groups created to disaggregate the scenarios, the characteristics associated to the FORM, LAYOUT and ORGANIZATION of the lighting systems in the space and the system assembly LOCATION in the environment may be considered.

The following examples illustrate the aspects approached in this item, taking the scenarios defined in this comparative study as the benchmark.

\subsubsection{Scenarios with lower and higher LPD energy performance}

A comparative analysis could be performed of the scenarios that presented the lowest and highest energy performance. As an example (Figure 9), we opted to present the scenario with the lowest and highest LPD, using the groups formed by the LEADING, COMPLEMENTARY and SUPPLEMENTARY LIGHTS.

Figure 9. Scenarios with the lowest and highest LPD

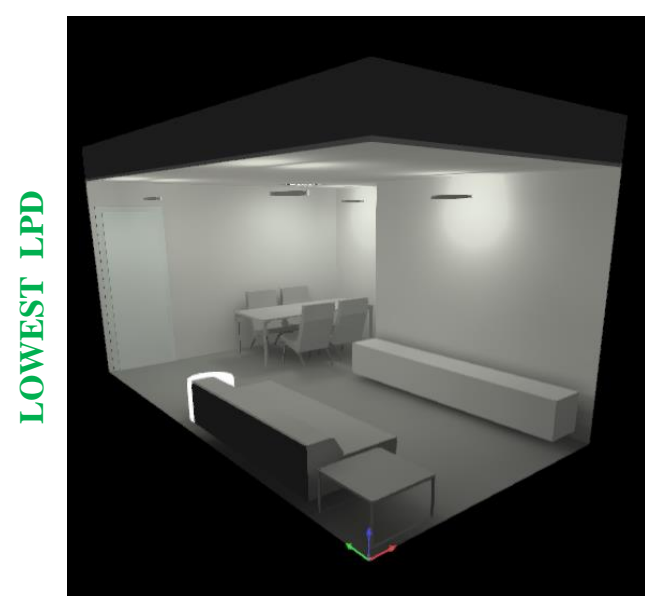

$4,09 \mathrm{~W} / \mathrm{m}^{2}$

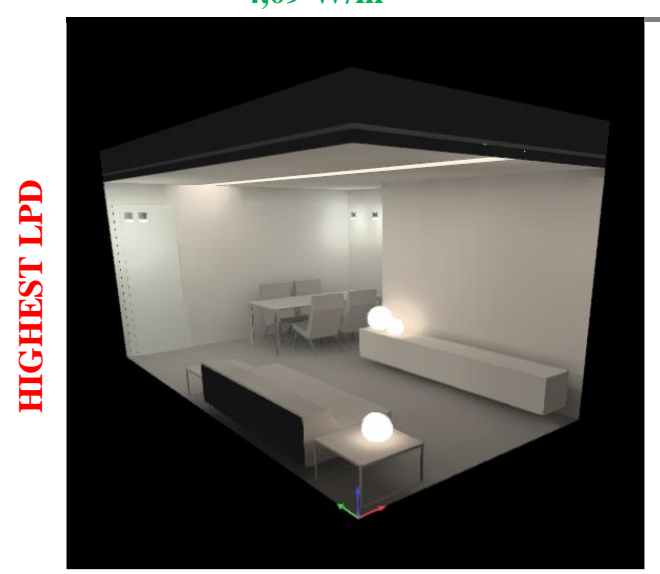

$13,61 \mathrm{~W} / \mathrm{m}^{2}$

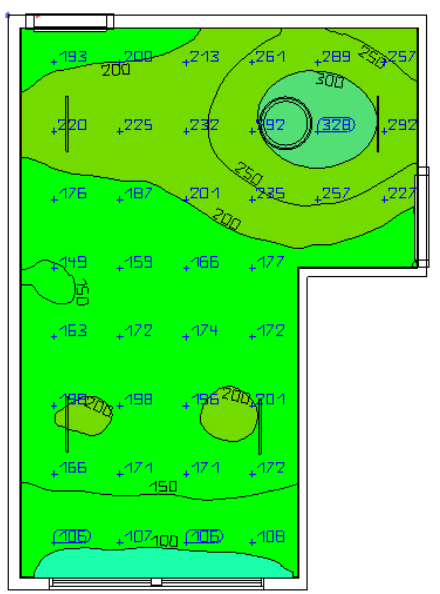

Matrix Data

Matrix: 5

Scenario: C15

EAverage: 172 lx

EMín/Average: 0,43

Matrix: M2

Scenario: C4

E Average: 297 lx

EMín/Average: 0,59

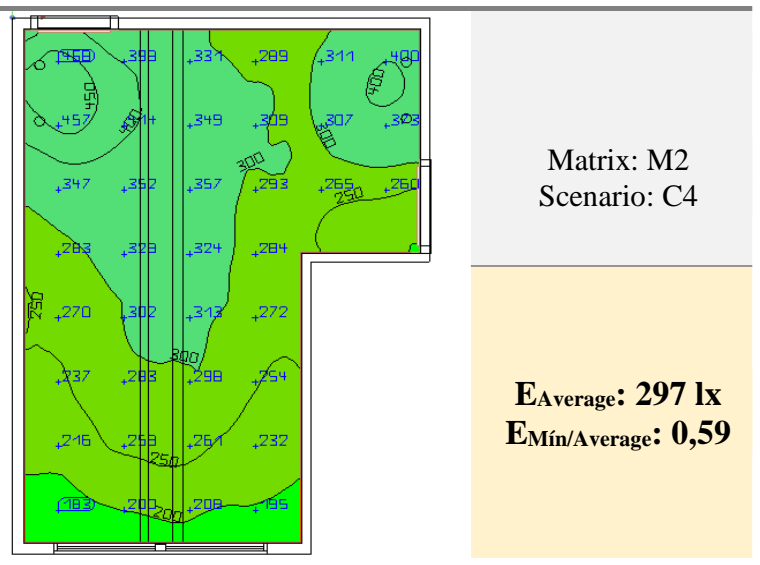

Isoilluminance

Note: Isoilluminance at working plane height. Mounting height $(\mathrm{MH})$ of pendant =2,20m. Source: Prepared by the Authors. Adapted from Moraes (2018).

As a result, it is observed that the lowest LPD value obtained by the group analysed is contained in Matrix 5, formed by a linear hanging LEADING LIGHT installed in the space. This scenario has a 4,09 $\mathrm{W} / \mathrm{m}^{2}$ LPD. The highest LPD was formed in Matrix 1, resulting from a scenario with cove lighting (in the 
ceiling), with a LPD energy performance of $13.61 \mathrm{~W} / \mathrm{m}^{2}$. The lighting effect produced by these scenarios results in a good lighting uniformity and similar levels, as shown in Figure 9.

\subsubsection{Form, Layout, Organization and Assembly location of the lighting}

The group of scenarios developed enables the energy behaviour of the lighting effect produced to be analyzed, using the FORM, LAYOUT, ORGANIZATION and assembly LOCATION variation as the parameter. These criteria prioritise the lighting effect produced by the different system in the environment provided by the luminaire FORM, and the arrangements formed by them in the environment:

\section{- The form variation of lighting systems}

It was opted for scenario C6 as an illustrative example, which has the LEADING LIGHT in the ceiling in a linear FORM, comparing its performance with the other scenarios - C1, C11, C16 and C21 - which have luminaires with individual, surface and volumetric FORMS, respectively, and coved lighting. These scenarios present an aligned ceiling LAYOUT and ordered ORGANIZATION, as demonstrated in Figure 10.

Figure 10. The different lighting effects produced due to a variation in form

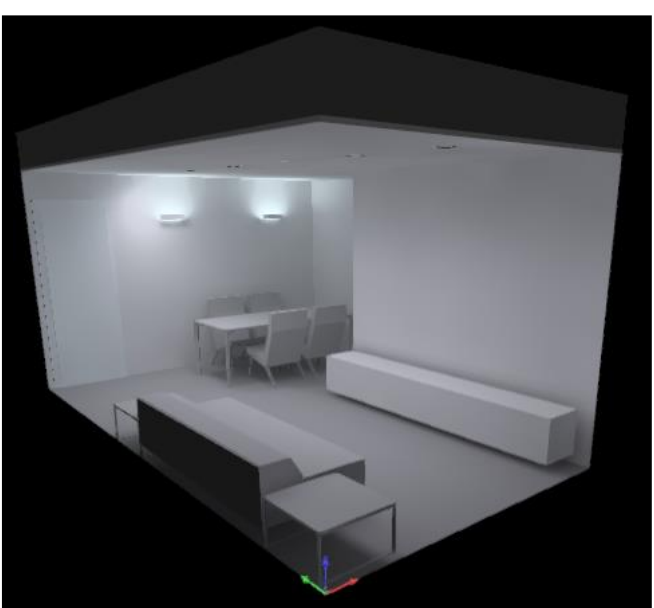

$4,84 \mathrm{~W} / \mathrm{m}^{2}$

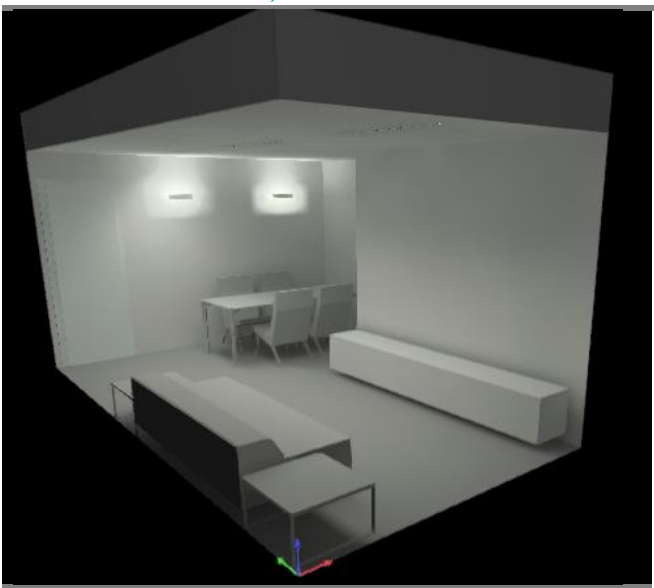

$6,67 \mathrm{~W} / \mathrm{m}^{2}$

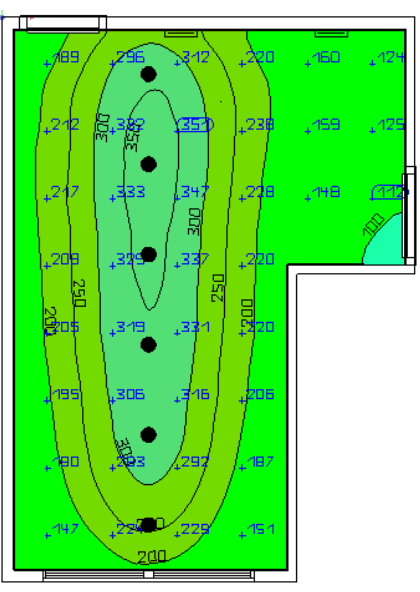

Isoilluminance

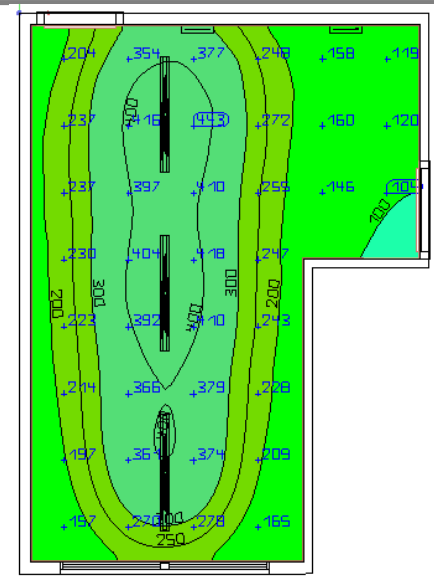

Isoilluminance

(cont.)

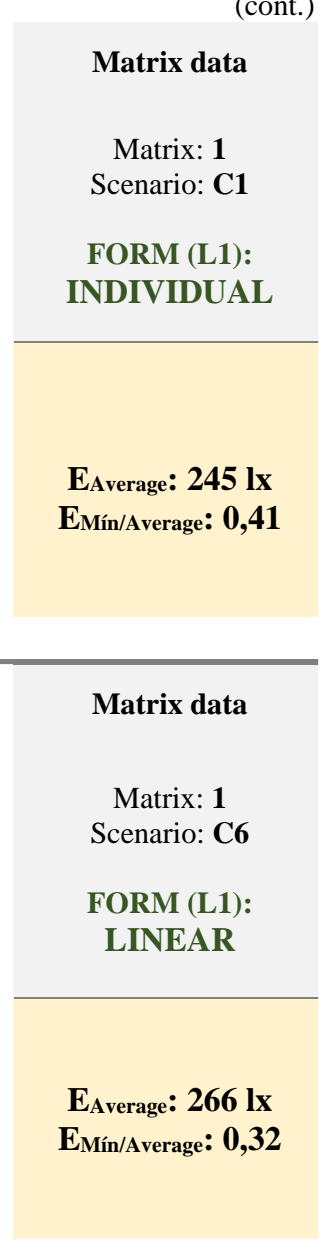

E Average: 266 lx

EMín/Average: 0,32 


\section{ACE Architecture, City and Environment}

E-ISSN 1886-4805

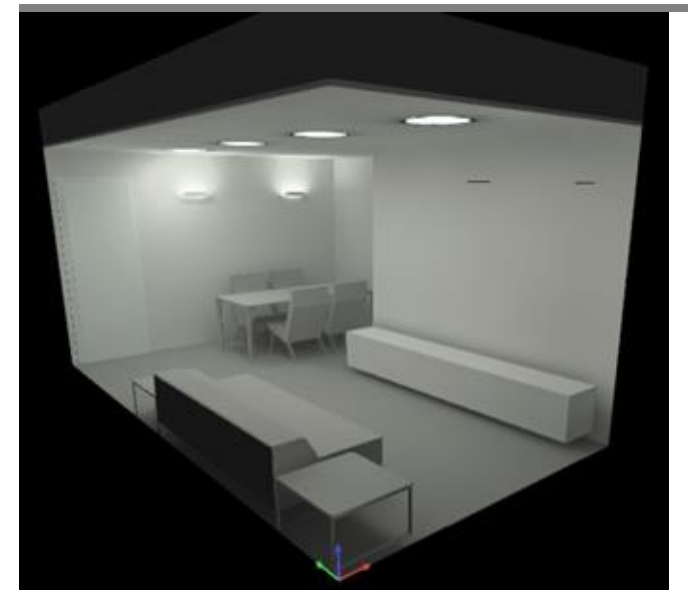

$4.35 \mathrm{~W} / \mathrm{m}^{2}$

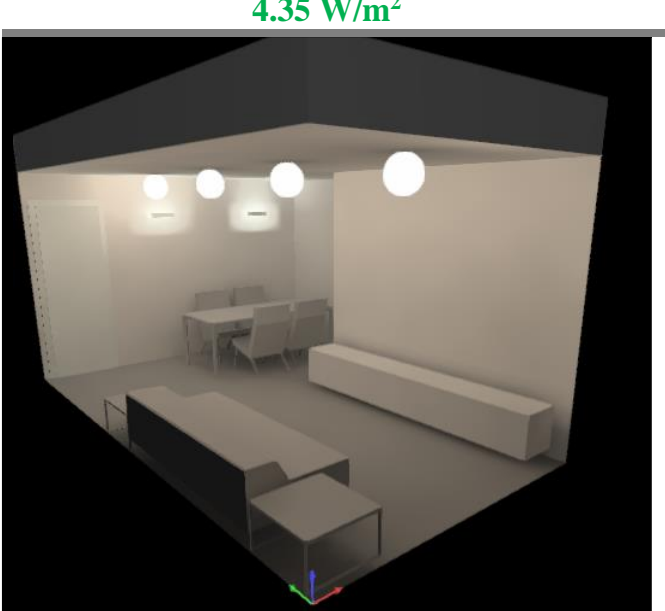

$5,78 \mathrm{~W} / \mathrm{m}^{2}$

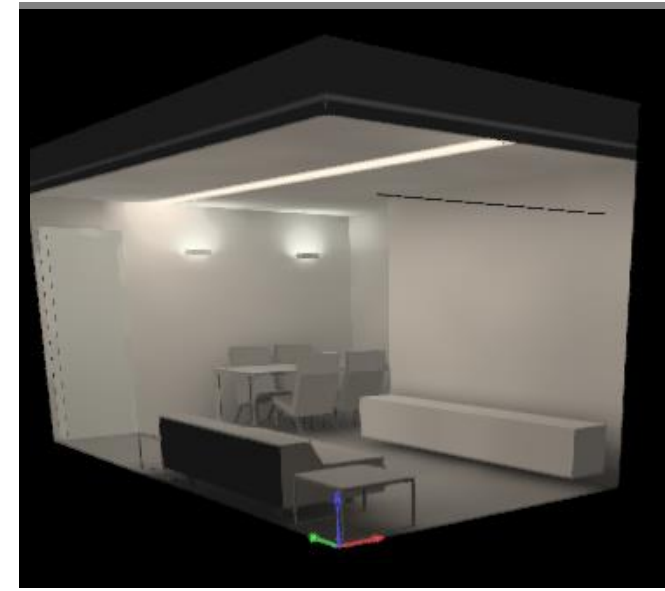

$10,38 \mathrm{~W} / \mathrm{m}^{2}$

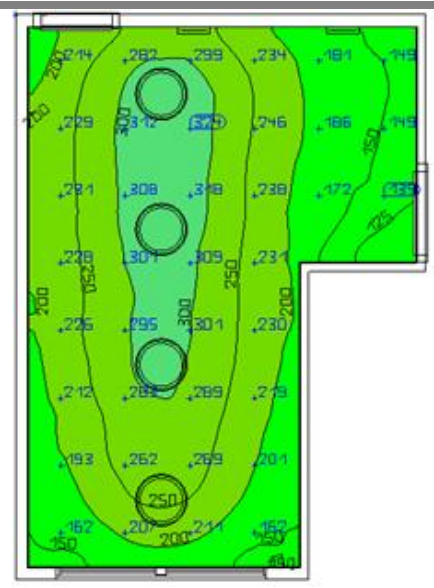

Isoilluminance

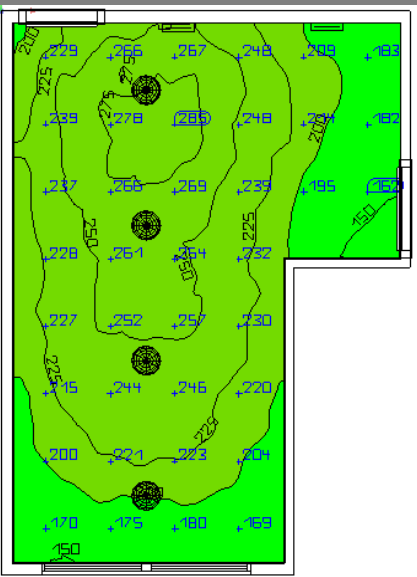

Isoilluminance

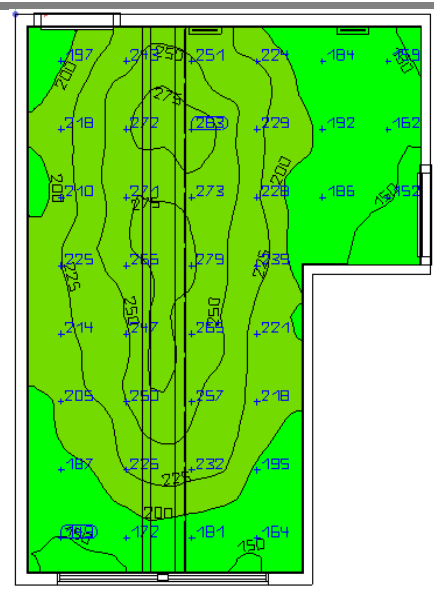

Isoilluminance
Matrix data

Matrix: 1

Scenario: C11

FORM (L1):

SURFACE

EAverage: 232 lx

EMín/Average: 0,48

E Average: 224 lx

EMín/Average: 0,59

Matrix: 1

Scenario: C16

FORM (L1):

VOLUMETRIC

E $_{\text {Average: }} 245$ lx

EMín/Average: 0,41

Note: Isoilluminance at working plane height. Source: Prepared by the Authors. Adapted from Moraes (2018).

With regards to energy performance, an approximately $2 \mathrm{~W} / \mathrm{m}^{2}$ increase was observed, if the lowest and highest LPD produced by the variation in the luminaire FORM in the scenarios evaluated are compared. The lighting effect produced by the lighting systems in the environment are also similar, not involving a significant increase in average lighting, with this aspect demonstrated in the isoilluminance curves of the simulated models (Figure 10). 


\section{ACE Architecture, City and Environment}

E-ISSN 1886-4805

- The Layout and Organization variation

The LAYOUT and ORGANIZATION of the lighting systems in the environment allow the variability of arrangements and lighting effects produced by a lighting system to be increased (Figure 11).

Figure 11. The different effects produced in the lighting due to the Layout and Organization variation

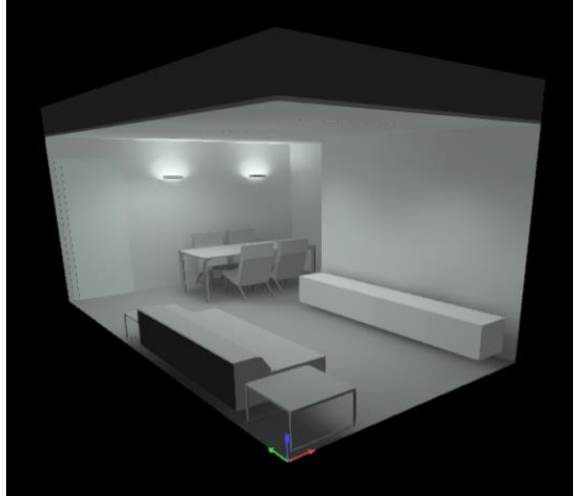

$6,67 \mathrm{~W} / \mathrm{m}^{2}$

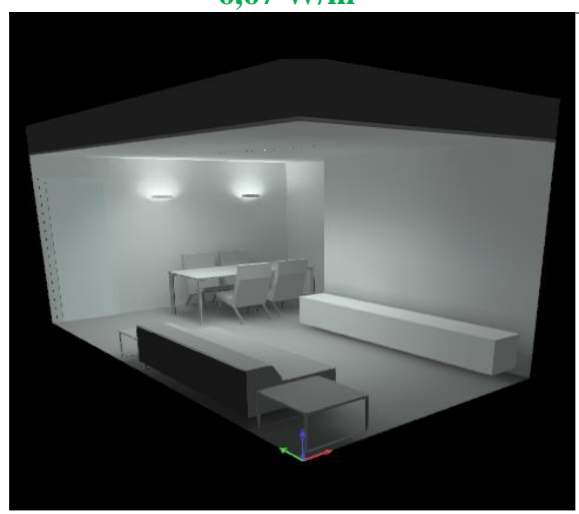

$6,67 \mathrm{~W} / \mathrm{m}^{2}$

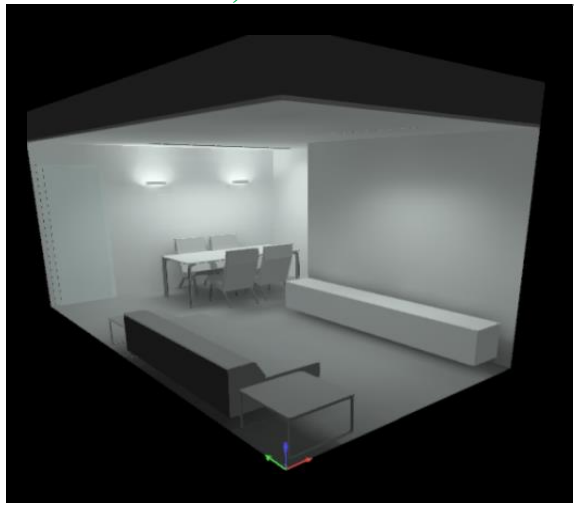

$6,67 \mathrm{~W} / \mathrm{m}^{2}$

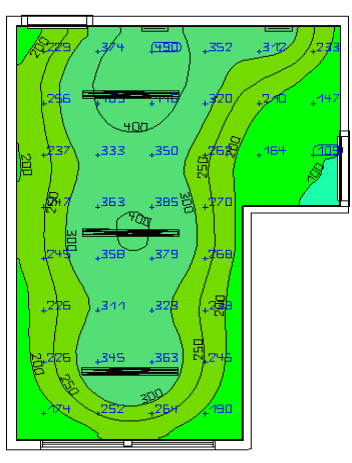

Isoilluminance

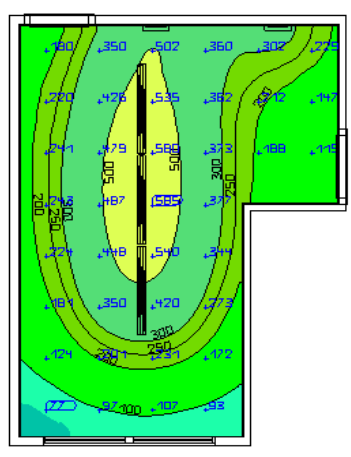

Isoilluminance

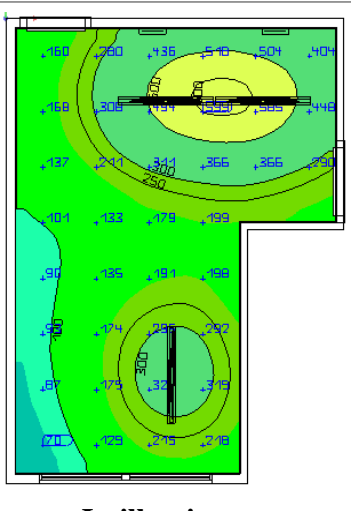

Isoilluminance

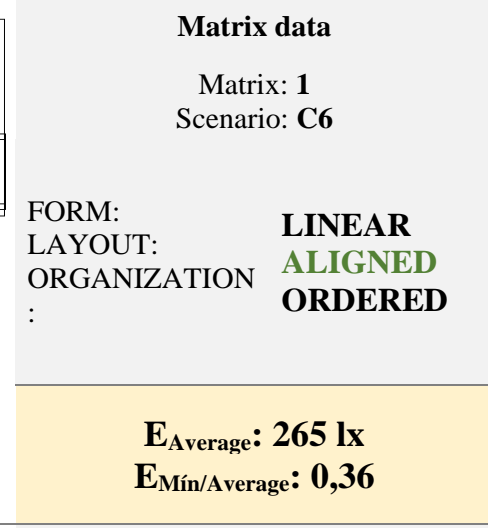

$\mathrm{E}_{\text {Average: }} 265 \mathrm{~lx}$

Matrix data

Matrix: 1

Scenario: C6

FORM:

LAYOUT:

ORGANIZATION

LINEAR

CLUSTER

ORDERED

E Average: 278 lx

E Mín/Average: 0,25

\begin{tabular}{|c|c|}
\hline \multicolumn{2}{|c|}{ Matrix data } \\
\hline \multicolumn{2}{|c|}{$\begin{array}{c}\text { Matrix: } 1 \\
\text { Scenario: C6 }\end{array}$} \\
\hline $\begin{array}{l}\text { FORM: } \\
\text { LAYOUT: } \\
\text { ORGANIZATION } \\
:\end{array}$ & $\begin{array}{l}\text { LINEAR } \\
\text { SINGULAR } \\
\text { ARBITRAR } \\
\text { Y }\end{array}$ \\
\hline $\begin{array}{r}\text { E }_{\text {Average: }} \\
\text { E }_{\text {Mín/Aver }}\end{array}$ & $\begin{array}{l}263 \text { lx } \\
\text { ge: } 0,22\end{array}$ \\
\hline
\end{tabular}

EMín/Average: 0,22

Note: Isoilluminance at working plane height. Source: Prepared by the Authors. Adapted from Moraes (2018).

Taking the previous scenario (C6) as a benchmark, Figure 11 shows the different effects produced in the lighting by the arrangements formed due to the LAYOUT and ORGANIZATION variation of the lighting system in a linear FORM. The LAYOUT and ORGANIZATION variation of the luminaires in the ceiling accentuate the light distribution differences in the environment for the same LPD, which is $6,67 \mathrm{~W} / \mathrm{m}^{2}$ in the case of scenario C6 (Figure 11). The arbitrary layout scenario favours lighting the dining table with higher luminous density. The scenario with an aligned layout distributes the

ACE, 15 (45) CC BY-ND 3.0 ES | UPC Barcelona, España | Residential Lighting Performance Indicators. DOI: 13 http://dx.doi.org/10.5821/ace.15.45.9536 
luminosity, providing a more uniform environment. To highlight the differences, both of the scenarios meet the specific aspects required for residential use.

\section{- Variation of the assembly location}

Variation of the lighting system assembly LOCATION in the environment increases the variability of arrangements and lighting effects served by a lighting system. Taking the previous scenario as a benchmark, (C6 with a linear FORM), Figure 12 demonstrates the variation in the lighting system installation LOCATION. The first scenario presents the light as the LEAD in the ceiling, and the second in the space (hanging).

With regards to the LPD, it was observed that the scenario with assembly in the ceiling achieved a $6,67 \mathrm{~W} / \mathrm{m}^{2} \mathrm{LPD}$, higher than the scenario with installation in the space (hanging) with 4,42 W/m². The height difference for lighting system installation - lower for the hanging light, including the luminaire 's photometric characteristics - is a parameter that contributes towards the lowest LPD value obtained in the scenario in the space (Figure 12). The luminous distribution produced by the semi-direct hanging systems contributed towards a greater lighting uniformity in the environment, if compared with the lighting system installed in the ceiling.

Figure 12. The different lighting effects produced due to a variation in the lighting system assembly location

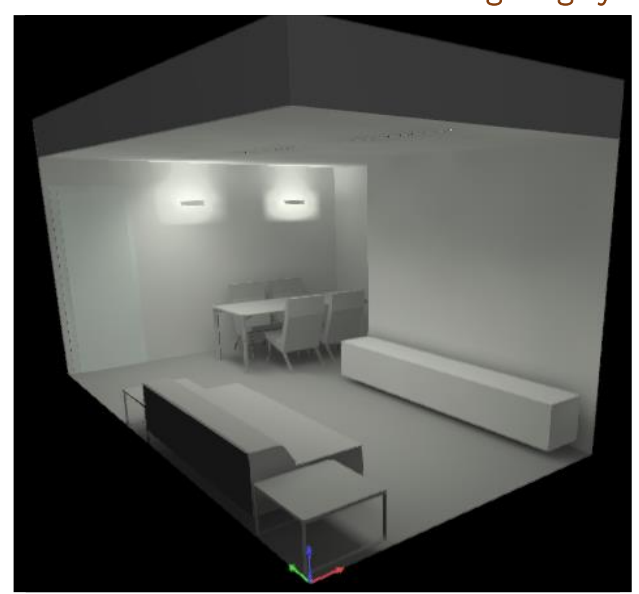

$6,67 \mathrm{~W} / \mathrm{m}^{2}$

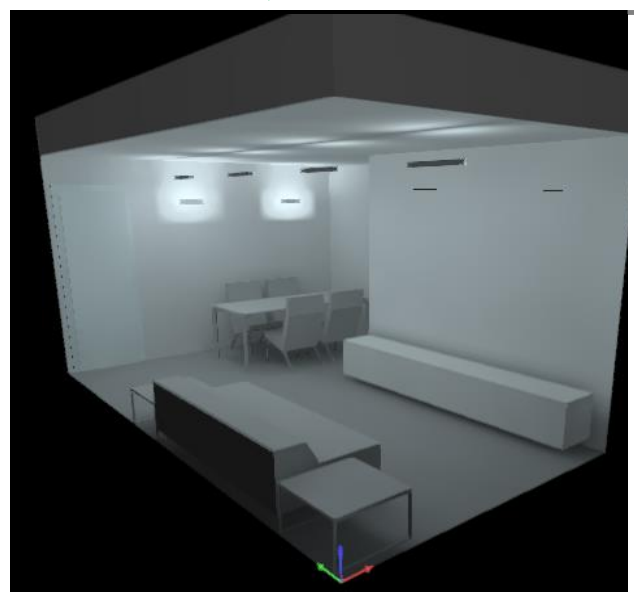

$4,42 \mathrm{~W} / \mathrm{m}^{2}$

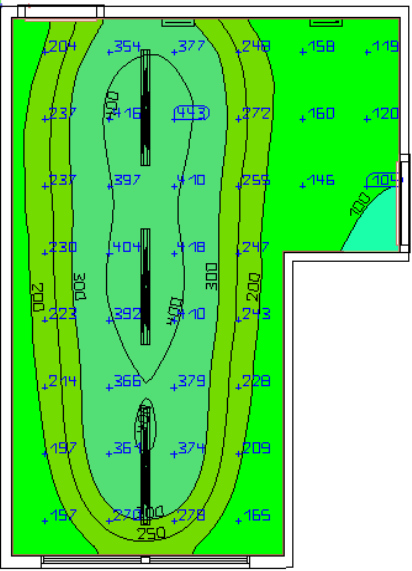

Isoilluminance

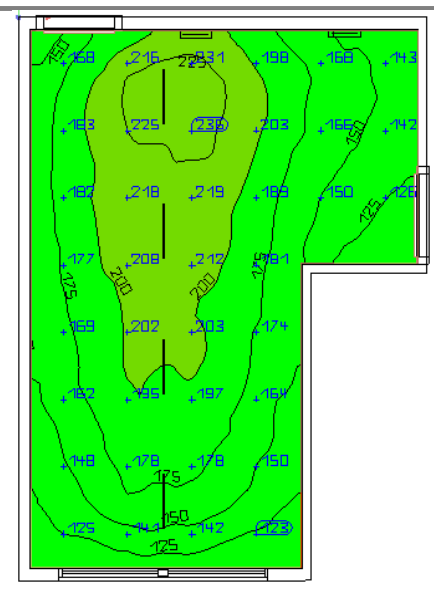

Isoilluminance

\section{Matrix data \\ Matrix: 1 \\ Scenario: C6 \\ Assembly LOCATION \\ (L1): CEILING}

E $_{\text {Average: }} 266$ lx

EMín/Average: 0,32

E $_{\text {Average: }} 175 \mathrm{~lx}$

$\mathbf{E}_{\text {Mín/Average: } 0,58}$

Note: Isoilluminance at working plane height. Mounting height $(\mathrm{MH})$ of pendant $=2,20 \mathrm{~m}$. Source: Prepared by the Authors. Adapted from Moraes (2018).

ACE, 15 (4.5) CC BY-ND 3.0 ES | UPC Barcelona, España | Residential Lighting Performance Indicators. DOI 


\subsection{Residential Artificial Lighting (RAL) indicators}

Application of the methodology that has residential environments as a benchmark - specifically considering the living/dining room - according to a set of intrinsically related indicators (Figure 13). They express fundamental aspects in RAL, moderated by the criteria of visual comfort, health and efficiency of the systems in the environment. Adjustments were made during the scenario creation process, since difficulties were encountered when consulting the virtual database of the companies defined in this study (Moraes, 2018).

It was observed that there are a lower number of LED lighting systems with a residential application, compared with those for the commercial sector. Added to this, the CRI found in the systems has values of close to $85 \%$. Systems with a value higher than $90 \%$ are practically inexistent in the database consulted (DIAL GmbH, 2019). The output ( $\eta$ ) from LED systems is higher than 45 lumens/W and is related to the requirements established by the California code (CEC, 2019; CLTC, 2016) for high performance LED systems.

Figure 13. RAL indicators from the living/dining room

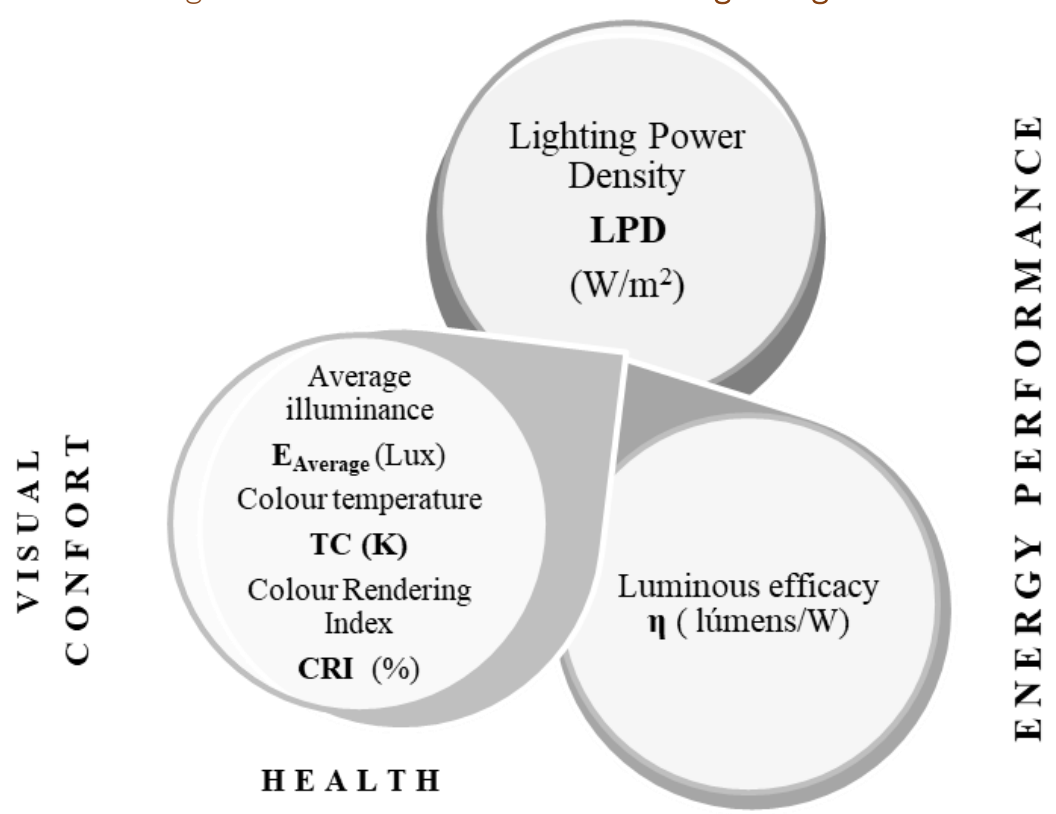

Source: Prepared by the Authors. Adapted from Moraes (2018).

The energy performance of the different lighting systems was estimated by procedures developed in this research, using models in which lighting scenarios were simulated. These scenarios were grouped together by performance bands (in LPD); common characteristics can be identified for each of these in Table 3 and Figure 8 . A LPD of up to $8 \mathrm{~W} / \mathrm{m}^{2}$ may be attributed as corresponding to the energy performance of the group of scenarios (approximately $70 \%$ of scenarios).

Table 3. Common characteristics of performance bands (in LPD)

\begin{tabular}{|c|c|}
\hline LPD & Recommendations \\
\hline $\begin{array}{c}0-5 \\
W / m^{2}\end{array}$ & $\begin{array}{l}0-3,5 \mathrm{~W} / \mathrm{m}^{2} \\
\text { Present scenarios that low illuminance, resulting from activities that require minimum levels, such } \\
\text { as relaxation, watching TV and other preferences related to the living room. } \\
3,5-5 \mathrm{~W} / \mathrm{m}^{2} \\
\text { The scenarios come from LEADING LIGHT and provide some examples of its interaction with the } \\
\text { COMPLEMENTARY and SUPPLEMENTARY LIGHT. These scenarios have illuminances between } 100 \\
\text { and } 200 \text { lux for meeting environmental activities. }\end{array}$ \\
\hline
\end{tabular}

ACE, 15 (4.5) CC BY-ND 3.0 ES | UPC Barcelona, España | Residential Lighting Performance Indicators. DOI: 15 http://dx.doi.org/10.5821/ace.15.45.9536 


\begin{tabular}{|c|l|}
\hline $\begin{array}{l}5-10 \\
\mathrm{~W} / \mathrm{m}^{2}\end{array}$ & $\begin{array}{l}\text { Most predominant group. Gathers a diversity of solutions and lighting effects to meet different } \\
\text { preferences with high energy performance. } \\
10-12 \mathrm{~W} / \mathrm{m}^{2} \\
\text { The scenarios meet the preference for higher illuminances, if compared to the others. } \\
\text { Designers who admit an additional strip to the previous one to meet requirements considered } \\
10-15\end{array}$ \\
$\begin{array}{l}\text { essential, related to the luminotechnical effect produced by light in space. } \\
12-15 \mathrm{~W} / \mathrm{m}^{2} \\
\text { It brings together the most complex and highly energetic scenarios when compared to the other } \\
\text { scenarios contained in the other bands. The effect of light produced in space is more important } \\
\text { than the most efficient solutions from an energy point of view. }\end{array}$ \\
\hline
\end{tabular}

Source: Prepared by the Authors. Adapted from Moraes (2018).

The living/dining room study demonstrated that joining the performance indicators considered the best practices available contributes towards the creation of various scenarios, with good use of light in environments, favouring the development of lighting system energy efficiency benchmarks.

The benchmarks imply that new indicators should be included, especially those related to new studies (Bará and Escofet, 2018; Lucas et al., 2014; SSL- erate, 2016) regarding health and visual comfort in homes. These indicators must be identified and included to those presented in this paper.

\section{Conclusions}

These research objectives aim to develop a set of procedures to evaluate artificial lighting performance indicators expressing the integrated performance of health, visual comfort and the efficiency of lighting systems in residential environments.

The analysis identified a gap in the literature regarding residential buildings while lighting indicators the commercial and services typologies present energy performance indicators, extensively described in literature. However, it seems to adopt an inadequate approach in the residential sector as presented earlier in the Introduction. This observation encouraged the study, focused on this paper (Moraes, 2018).

A literature review identified best practices in California (CEC, 2019; CLTC, 2016), which is innovative, since it introduces indicators that contribute towards visual comfort and health in homes. However, it was observed that this code presents requirements that focus on the energy efficiency of artificial lighting.

The option of lighting classifications, with an emphasis on the lighting effect, oriented by the FORM, LAYOUT and ORGANIZATION (Muros Alcojor, 2012) of the lighting systems, was considered the most appropriate for this study, since it considers the space/effect relation of the lighting produced in the environment. The design method was expanded to comply with lighting residential environments, including the specification of the assembly LOCATIONS of the systems contained in the environment, which favours the determination of multiple scenarios (Moraes, 2018).

With regards to energy efficiency indicators, the output - $\eta(\mathrm{lm} / \mathrm{W})$ - is related to the object (luminaire). For this reason, it should be used with other indicators, in an integrated manner. The indicators related to the effect produced in the space, the LPD $\left(\mathrm{W} / \mathrm{m}^{2}\right)$, has a wide-ranging RAL application.

The band with the best results was obtained with a LPD of between 3,5 and $10 \mathrm{~W} / \mathrm{m}^{2}$. Simulations suggest that between the different RAL configurations in the examined environment, the scenarios with a LEADING LIGHT in the SPACE present the best results for energy efficiency and lighting distribution in the environment, followed by the performance observed by the systems installed in the CEILING. This result may be attributed to the height of the hanging luminaire assembly plan, which favours the luminous efficacy of the group of scenarios, with a LEADING LIGHT in the SPACE. 
The variation in the luminaire FORM in the environment demonstrated impacts in the LPD for the energy efficiency obtained. The LAYOUT and ORGANIZATION variation of the luminaires in the environment studied directly affects the illuminance distribution and, consequently, produces different lighting effects, with a higher or lower variation in luminous intensity in the environment, depending on the resulting arrangement.

Although the scenarios that use non-visible lighting source (cove) show the highest LPD performance among the scenarios examined. Results point out to the possibility of using this lighting system with energy performance within the above mentioned range.

It is expected that discussion of this topic attracts the interest of designers and users, in order to disseminate its performance. It will be possible to assign specific values to the various applications in existence in the residential area. A virtuous circle will be created as a consequence to measure and surpass performance, and then improve aspects of health, visual comfort and energy performance in homes.

The objective of this study aims to collaborate towards the establishment of a position in which knowing the performance of artificial lighting systems becomes a habit. As a consequence, it is expected that this contributes towards improvements in residential projects and integrates visual aspects with those related to efficiency in homes.

\section{Acknowledgements}

This research was conducted with support from the Coordination Agency for the Improvement of Higher Education Personnel - Brazil (CAPES).

\section{Authorship}

This paper is part of the first Author's doctoral thesis: "Indicadores da iluminação artificial em ambientes residenciais". Both, second, and third authors are advisors of the Thesis, have revised it critically for important intellectual content.

Conflict of interests: Author declares no conflict of interests.

\section{References}

ASHRAE - American Society of Heating, R. and A.-C. E. (2019). ANSI/ASHRAE/IES Standard 90.1-2019 Energy Standard for Buildings Except Low-Rise Residential Buildings. USA: ASHRAE.

Bará, S., and Escofet, J. (2018). On lamps, walls, and eyes: The spectral radiance field and the evaluation of light pollution indoors. Journal of Quantitative Spectroscopy and Radiative Transfer, 205, 267-277. DOI: https://doi.org/10.1016/j.jgsrt.2017.09.022

CEC - California Energy Commission. (2019). Residential Compliance Manual. For The 2019 Building Energy Efficiency Standards Title 24, Part 6, and Associated Administrative Regulations In Part 1. California: CEC.

CEN - European Committee for Standardization. (2011). BS EN 12464-1. Light and lighting - Lighting of work places. Part 1: Indoor work places. UK: CEN.

CLTC - California Lighting Technology Center. (2016). What's new in the 2016 code? Residential Lighting. Changes to mandatory lighting requirements in California's 2016 Building Energy Efficiency Standards California's. Davis, USA. Retrieved from https://cltc.ucdavis.edu/publication/2016-title-24code-changes-residential

ACE, 15 (4.5) CC BY-ND 3.0 ES | UPC Barcelona, España | Residential Lighting Performance Indicators. DOI 17 http://dx.doi.org/10.5821/ace.15.45.9536 
Degra, A. (2014) Residência em São Paulo, Lume Arquitetura, 71, 33-38.

DIAL GmbH (2018) DIALux evo 8. Version history, DIAL GmbH. Retrieved from https://www.dial.de/en/software/dialux/versionhistory/dialux-evo-80

DIAL GmbH (2019) LUMsearch DIAL. Easy search for luminaires online, DIAL GmbH. Retrieved from https://www.dial.de/en/home

Figueiro, M., Nagare, R. and Price, L. (2018). 'Non-visual effects of light: How to use light to promote circadian entrainment and elicit alertness', Lighting Research \& Technology, 50(1), pp. 38-62. DOI: https://doi.org/10.1177/1477153517721598

IES - Illuminating Engineering Society. (2013). The Lighting Handbook - 10th Edition. Nova York: IES.

ISO - International Organization for Standardization. (2002). ISO 8995-1. Lighting of work places - Part 1: Indoor. Geneva: ISO.

Lucas, R. J., Peirson, S. N., Berson, D. M., Brown, T. M., Cooper, H. M., Czeisler, C. A., Figueiro, M. G., Gamlin, P. D., Lockley, S. W., O’Hagan, J. B., Price, L. L. A., Provencio, I., Skene, D. J., and Brainard, G. C. (2014). Measuring and using light in the melanopsin age. Trends in Neurosciences, 37(1), 1-9. DOI: https://doi.org/10.1016/j.tins.2013.10.004

Moraes, J. S. de, Muros Alcojor, A. and Bittencourt, L. S. (2018). 'Análise de indicadores de desempenho da iluminação artificial em ambientes residenciais', PARC Pesquisa em Arquitetura e Construção, 9(1), 35-46. DOI: https://doi.org/10.20396/parc.v9i1.8650219

Moraes, J. S. de, Muros Alcojor, A. and Bittencourt, L. S. (2020) 'Avaliação integrada do desempenho visual e eficiência energética pelo DIALux evo 8 para projetos de iluminação artificial', PARC Pesquisa em Arquitetura e Construção, 11, e020005. DOI: https://doi.org/10.20396/parc.v11i0.8653991

Moraes, J. S. de. (2018). Indicadores da iluminação artificial em ambientes residenciais (Tesis doctoral). Retrieved from http://www.repositorio.ufal.br/handle/riufal/5648

Muros Alcojor, A. (2012) La Luz: De herramienta a lenguaje. Una nueva metodología de iluminación artificial en el proyecto arquitectónico (Tesis doctoral). Retrieved from http://hdl.handle.net/2117/94604

Nagare, R., Plitnick, B. and Figueiro, M. (2019). 'Effect of exposure duration and light spectra on nighttime melatonin suppression in adolescents and adults', Lighting Research \& Technology, 51(4), pp. 530-543. DOI: https://doi.org/10.1177/1477153518763003

Rea, MS., Figueiro, MG., Bierman, A and Bullough, JD. (2010). 'Circadian light.', Journal of circadian rhythms, 8(1), 2. DOI: https://doi.org/10.1186/1740-3391-8-2

SSL - The Society of Light \& Lighting. (2009). The SLL Lighting Handbook, The Society of Light and Lighting. London: CIBSE.

SSL - The Society of Light and Lighting. (2013). Lighting Guide 9: Lighting for Communal Residential Buildings. London: CIBSE.

SSL- erate (2016). Lighting for Health and Well-Being in Education, Work Places, Nursing Homes, Domestic Applications, and Smart Cities. UE: SSL-erate. Retrieved from http://lightingforpeople.eu/2016/wp-content/uploads/2016/03/SSLerate-3.2-3.4-v4.pdf 